\title{
DISSERTAÇÕES DE MESTRADO E TESES DE DOUTORADO/2000
}

Universidade Federal do Rio de Janeiro

Centro de Filosofia e Ciências Humanas

Instituto de Psicologia

Programa de Pós-graduação em Teoria Psicanalítica

\section{MESTRADO}

Autora: Silvia Carvalho da Fonseca

Título: Sublimação e melancolia:

\section{aproximações}

Orientadora: Maria Teresa Pinheiro

Data de defesa: fevereiro

Esta dissertação aborda as relações entre sublimação e melancolia na obra de Freud. Seu objetivo é problematizar a questão da constituição da subjetividade na meIancolia. Enquanto destino de criação, a sublimação vai estar associada à feminilidade mediante o reconhecimento do desamparo. Pela criação o melancólico poderá talvez servir-se do nada, do vazio, dele fazendo recobrimento ao insuportável da perda.

Autora: Irene Gondim Grether

Título: Transferência e compulsão

à repetição: a imposição da dimensão no discurso freudiano Orientador: J oel Birman

Data de defesa: março

Esta dissertação tem como objetivo o estudo da presença da dimensão intensiva no discurso freudiano. Partimos da suposição de que Freud tinha inicialmente um projeto científico para a psicanálise, no qual pretendeu estabelecer a subordinação das intensidades, transformando-as em representação, tendo como suporte teórico de base o conceito de inconsciente. Foi deslocando paulatinamente a sua prática em direção a uma clínica do irrepresentável, o que determinou os desdobramentos metapsicológicos dos anos 15, as transformações do estatuto do conceito de pulsão no interior de sua obra e o inteiro reconhecimento da problemática da repetição. Culminou na postulação de uma nova dualidade pulsional, na ampliação do conceito de transferência, e na admissão da dimensão econômica. Para fazer este percurso, procedemos, inicialmente, a um estudo dos antecedentes de Freud, no que diz respeito à influência de outros saberes, de forma a fundamentar a nossa percepção de que há um paradoxo nas suas relações com a ciência, e que isto estaria de al guma forma presente na constituição da psicanálise e nas rupturas de seu discurso. Em seguida, fizemos uma análise teórica da questão da repetição, tentando demonstrar sua dimensão de compulsão e, em decorrência disso, buscamos estabelecer suas articulações na transferência, aliadas às categorias de amor e saber. Nosso encaminhamento nos remeteu, então, a um trabal ho junto aos textos clínicos e artigos que versam sobre a técnica, buscando fazer uma revi- 
são dos momentos em que esse embaraço se fez presente, dando especial atenção aos relatos do Homem dos Lobos e do Homem dos Ratos. Ao final, este trabalho se abre para a consideração de que, com a presença da dimensão intensiva no interior do aparelho, não há mais uma verdade inconsciente a ser revelada, sendo inúmeras as possibilidades para a reconstrução da história subjetiva. Neste caso, a dimensão criativa, então, se impõe e, no percurso freudiano se sobrepõe o pólo da imaginação ao pólo da razão.

Autora: Heloisa Helena Pinto Portela da Silva

Título: Amor ao estrangeiro: uma possibilidade de erotismo nos dias atuais

Orientador: J oel Birman

Data de defesa: março

A presente dissertação aborda a relação amorosa, não apenas sob o ponto de vista da psicanálise, mas também pela perspectiva da trama social da contemporaneidade. A relação amorosa manifesta-se como um importante e complexo destino da pulsionalidade humana. No primeiro capítulo, o leitor é levado em uma jornada pela metapsicologia freudiana, delimitando conceitos fundamentais como o de pulsão e descrevendo suas vicissitudes descritas por Freud em 1915. Como as ordens social e política de cada época instrumentalizam as produções subjetivas, no segundo capítulo, viaja-se pelas formações da estrutura social da pósmodernidade, delineando aspectos importantes como sua ênfase no narcisismo, seu imediatismo e o culto à imagem e ao consumo. Isto caracteriza um enredo cultural da atualidade que impõe um certo estilo de relação amorosa. Por fim, o terceiro capítulo sugere outra alternativa para relacionamentos, o que é chamado de amor ao estrangeiro, um amor que foge à norma do espetáculo e combina ambas as correntes de afeição e sensualidade, amor e paixão.

Autora: Maria Celina Nina Bernardes

Título: 0 sujeito entre

sobredeterminação e escolha

Orientadora: Angélica Bastos

Data de defesa: abril

Esta dissertação percorreu na obra freudiana o conceito de sobredeterminação e a expressão "escolha da neurose". Traçou-se de que forma Freud construiu a idéia de sobredeterminação dos sintomas, para depois delinear como ele se deparou com a expressão "escolha da neurose". Desenvolvemos a idéia do determinismo no pensamento científico, tomando a física clássica como modelo, para assim diferenciar desse campo a noção freudiana de sobredeterminação. Esse conceito de Freud rompe com as idéias científicas de continuidade, previsibilidade e linearidade entre antecedentes e conseqüentes. A questão da estrutura foi abordada e possibilitou-nos mostrar como a estrutura da linguagem implica que as significações não sejam preestabelecidas ou mesmo fixas, e que ao sujeito cabe uma decisão quanto ao sentido. Pensar a escolha na psicanálise era 0 alvo desse trabalho. Abordamos que a questão da escolha na teoria psicanalítica diferencia-se da idéia de uma liberdade de escolha. A distinção entre causa e lei no pensamento psicanalítico nos permitiu integrar as idéias de escoIha e sujeito. 
Autora: Simone Ravizzini

Título: 0 que não podem dizer as palavras - o limite da interpretação Orientadora: Anna Carolina Lo Bianco Data de defesa: abril

O conceito de interpretação apresenta distinções no campo analítico. Lacan se apropria, guiado pelo discurso freudiano, com o intuito de subverter o que até então descrevia-se como sua função. Delimitar a interpretação torna-se crucial a quem exerce a psicanálise. Sob este prisma, buscou-se elaborar as contribuições de Lacan que situam a interpretação em seu avesso, distinta de um esclarecimento. Tal esforço resultou numa valorização da dimensão fora do significado, amparada pelas contribuições da lingüística moderna e justificada em uma leitura do rico trabalho deixado por Freud.

Autora: Lia Fernandes Ribeiro

Título: 0 olhar do engano considerações sobre o outro primordial na constituição do sujeito Orientadora: Ana Beatriz Freire

Data de defesa: abril

Esta dissertação se insere no âmbito da investigação sobre a constituição do sujeito. Tem por referências teóricas fundamentais as obras de Freud e Lacan. Parte de um caso clínico de autismo como base para a indagação acerca do processo pelo qual o infans vem a ser introduzido no campo da linguagem, no universo humano do sentido. Como agente fundamental desta passagem se situa o Outro primordial na forma particular de um olhar que é capaz de ope- rar uma transformação face ao real da criança. Trata-se, paradoxalmente, do olhar do engano.

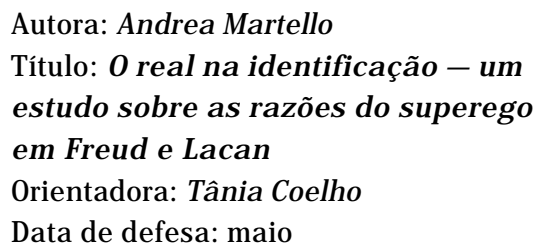

O objetivo desta dissertação é analisar o superego como limite da identificação, tal como esclarecido por Freud e Lacan. O superego é a instância por meio da qual se atualiza o conceito de pulsão, definindo-o a partir de um vínculo estreito entre a clínica do particular e a organização legiferante da civilização. Em última instância, Freud nos apresenta o superego como um reduto pulsional do que é operado pela identificação, gerador de um mal-estar intrínseco à organização social . Lacan, com a estrutura do significante, aprofunda a condição de falta do sujeito, destinando-o a ser um sujeito sempre por identificar-se e designando ao superego a potência do significante puro que impõe a lei da castração em sua vertente real . Partindo do mal-estar na civilização pensado por Freud, Lacan define o estatuto ético para a psicanálise. No entanto, essa ética só poderá ser melhor formulada quando o aspecto real do significante, ou da castração - que a princípio é imposto pelo superego - for pensado pela perspectiva do objeto a e pelo modo de relação com o gozo que isso implica. 
Autora: Alzira Costa de Oliveira

Título: Da afasia à fala, da neurologia à psicanálise: um percurso freudiano

Orientador: Waldir Beividas

Data de defesa: maio

Esta dissertação tem como objetivo o estudo das afasias e seus desdobramentos do campo da Neurologia para a Psicanálise, passando pela Lingüística e chegando às suas repercussões na atualidade. Procedemos, inicialmente, à análise do texto de Freud, sobre as afasias, cuja grande novidade é um esboço de aparelho de linguagem, contrapondo-se às áreas demarcadas e secionadas pela neurologia da época, constituindo desse modo o cerne do que podemos chamar de passagem da afasia à fala. Para expor as idéias freudianas sobre o tema, fizemos um levantamento histórico e panorâmico do campo de Neurologia, que serviu de referência a Freud, seus antecedentes e articulações de então. Por outro lado, investigamos os aspectos complementares e críticos que a lingüística tem, quanto ao trabalho de Freud, e tomamos Jakobson para ilustrar a visão da lingüística sobre as afasias. Procedemos, ainda, à análise das repercussões das idéias referentes à linguagem, até os autores atuais e suas contribuições. Ficou patente nessa análise 0 reforço às idéias de Freud, além da discriminação de diferentes visões sobre 0 texto freudiano das afasias, o que abre um espaço para novos questionamentos. Finalizo o percurso com a junção das visões da Neurologia e da Psicanálise. Em conclusão, o exame do tema se volta para a questão inicial: um texto, calcado no orgânico, propicia a passagem ao psíquico e, mais amplamente, à construção da própria psicanálise, levando-nos a con- cluir, junto com Freud, que a afasia não é dada pela simples lesão corporal, mas, como todo sintoma, é pela linguagem no corpo que se faz presente.

\section{Autora: Ivana Nunes Vieira}

Título: Sobre a associação livre

Orientador: Waldir Beividas

Data de defesa: maio

0 tema pesquisado foi o funcionamento da associação livre - a regra fundamental da psicanálise. No início da pesquisa, foi formulada a seguinte questão: qual substrato teórico poderíamos encontrar na literatura psicanalítica, principalmente em Freud e Lacan, que explicasse 0 funcionamento da associação livre? Para desenvolvêla, descrevemos o histórico do tema e o contexto em que ocorreu a sua formulação. Em seguida, e ainda guiado pela questão inicial, o trabalho expõe a conceituação de processo primário, a fim de relacionar a associação e o inconsciente. A partir disso, passa à discussão a respeito da metáfora e da metonímia, contribuição Iacaniana acerca do tema.

Autora: Rosa Alba Sarno Oliveira

Título: Sobre uma possível clínica psicanalítica das psicoses

Orientadora: Angélica Bastos

Data de defesa: maio

Tomando como ponto de partida a prática clínica com pacientes psicóticos, são investigados e desenvolvidos elementos, dentro da obra de S. Freud e do ensino de J. Lacan, que permitem argumentar em favor de uma possível clínica psicanalíti- 
ca das psicoses. De início, examina-se 0 próprio lugar que a questão da psicose ocupa com relação à psicanálise. Em seguida, aborda-se a problemática do sujeito na psicose, tomando como referência o imperativo freudiano que afirma que, como efeito do inconsciente, um sujeito deve advir. Nesta perspectiva, as formulações sobre a causalidade psíquica das psicoses são analisadas a partir do que define a causalidade para a psicanálise, em que determinação envolve responsabilidade, assim como causa pressupõe consentimento. E a foraclusão do significante do Nome do Pai é trabalhada como designando a posição do sujeito na psicose. 0 significante do Nome do Pai é tratado a partir da função da qual ele é operador, sendo em torno disto que é desenvolvido o que vai constituir o sujeito psicótico. Por fim, são feitas considerações sobre a transferência na psicose, sendo examinado o apelo à significação que caracteriza estes sujeitos. E analisa-se o que é imprescindível para a operação do sujeito suposto saber, verificando-se que, em seu plano mais fundamental, ele não é incompatível com o que define o sujeito psicótico.

Autor: Maurício J osé D’ Escragnolle Cardoso

Título: Tragédia e mito no helenismo francês, na filosofia de Nietzsche e em Freud e Lacan

Orientadora: Tânia Coelho dos Santos

Data de defesa: junho

Esta pesquisa busca percorrer os subsídios para a postulação de um conceito de trágico específico para a psicanálise, no intuito de dar os fundamentos necessários para uma discussão sobre a ética da psicanálise, assim como sobre as relações de continuidade e descontinuidade entre as visadas de Freud e Lacan. Em relação aos dois psicanalistas, a tese realiza um levantamento dos momentos e comentários onde a tragédia, o mito, e seus temas correlatos aparecem em suas obras. No intuito de garantir a interlocução necessária, foram postos em relevo outros dois discursos que se propõem a interpretar o sentido da tragédia. Por outro lado, o moderno helenismo francêse, por outro, a filosofia de Nietzsche.

\section{Autora: Marcela Cruz de Castro Decourt Título: Para além do pai está o homem: a função paterna de Freud a Lacan \\ Orientadora: Tânia Coelho dos Santos \\ Data de defesa: junho}

Esta dissertação tem como proposta percorrer o caminho de Freud a Lacan, no que diz respeito à lei do pai, permitindo a construção de uma reflexão rigorosa acerca do declínio da função paterna na contemporaneidade, bem como a análise de seus efeitos sobre a clínica psicanalítica. Inicialmente, privilegiamos o conceito de estrutura a fim de detectar a sua particularidade no campo da psicanálise. Passamos, então, à lógica do significante, procurando delimitar sua relação com o funcionamento inconsciente. A seguir, desenvolvemos o conceito de inconsciente de Freud a Lacan, apontando as revisões sofridas por este ao longo do percurso teórico e apresentamos a partir das contribuições de Jacques-Alain Miller, uma discussão sobre a relação entre o significante e o gozo na obra lacaniana. Realizamos em seguida uma apresentação dos principais mitos freudianos, com 0 
objetivo de extrair a função paterna subjacente a eles. Mapeadas estas referências, buscamos a novidade, introduzida por Lacan, neste retorno a Freud, onde 0 conceito de castração é o operador estrutural de que nós nos servimos para compreendermos o "para além do Édipo" lacaniano. Por fim, apresentamos a trajetória do declínio da função paterna de Freud a Lacan e, com isso, fomos capazes de identificar seus efeitos clínicos. Ao final deste trabalho pudemos sustentar a hipótese de que os novos sintomas parecem ser produto do desvelamento da inconsistência deste Outro que, na contemporaneidade, assume sua vertente tirânica, impondo aos sujeitos um gozo devastador, muitas vezes incompatível com a vida.

Autora: Graziele Maia

Título: 0 enigma da diferença sexual

e sua relação com o amor e os modos de amar

Orientadora: Anna Carolina Lo Bianco

Clementino

Data de defesa: julho

A presente dissertação examina a vida amorosa, em seus paradoxos, sob o ponto de vista da constituição psíquica. A constituição psíquica é entendida através dos conceitos de estrutura e de pulsão. Em relação ao primeiro, abordamos a organização sexual tendo em vista os estádios de desenvolvimento libidinal, de complexo de castração e de complexo de Édipo. A questão central neste ponto é a diferença sexual que vai determinar tanto a entrada quanto a saída do sujeito da problemática edipiana. A instituição de modos de amar baseados numa "lógica fálica", distintos em homens e mulheres, é igualmente conseqüência da dissolu- ção do Édipo. Em relação ao conceito de pulsão, trabalhamos a dualidade pulsional, pulsão de vida - pulsão de morte, constitutiva de todo sujeito, a pulsão de vida visando a união, a constância, a manutenção do vínculo amoroso, enquanto a pulsão de morte visa o rompimento da constância, a destruição do vínculo. Vemos que é a combinação de ambas que caracteriza a diversidade nos encontros amorosos e as possibilidade da criação.

Autor: Roberto Pires Calazans Matos

Título: A disjunção entre os domínios ético e científico e sua importância para a consideração do problema do sujeito

Orientadora: Angélica Bastos de Freitas

Rachid

Data de defesa: julho

Partindo do axioma psicanalítico "o sujeito sobre o qual operamos em psicanálise só pode ser o sujeito da ciência" este estudo discute a importância de determinar um campo próprio às questões do sujeito tal como são pensadas pela psicanálise. Esta discussão é enfocada por três distinções consideradas cruciais para esta determinação: a distinção entre 0 mundo antigo e o universo moderno; a distinção entre o domínio ético e o domínio científico, e a distinção entre a proposta psicanalítica e a proposta filosófica a respeito do sujeito. A primeira distinção diz respeito ao corte entre 0 mundo antigo e o mundo moderno, efetuado pelo advento da ciência moderna. Este corte se caracteriza pela destruição da referência absoluta que havia na cosmologia aristotélica e produz, como efeito, a busca de uma nova referência. Esta referência ausente torna o homem um deso- 
rientado no universo moderno. É nesta problemática - da referência ausente que surge a questão do sujeito moderno. 0 outro efeito do corte epistemológico é a distinção entre assuntos do domínio ético e assuntos do domínio científico. Por ser própria à época moderna, a distinção entre os domínios assume, neste estudo, a função de fio condutor. Este estudo se utiliza de tais distinções ao tratar da articulação interna dos conceitos freudianos, uma vez que uma expressão de Freud - pulsão de saber - pode levar a confundir os domínios ético e científico e a tornar imprecisa a determinação do campo da práxis analítica. 0 estudo conclui apontando a questão da subversão sobre o sujeito - tal como é entendido pela filosofia - efetuada pela psicanálise e ressaltada por Lacan.

Autora: J acila Maria da Silva

Título: A música da psicanálise - um estudo da singularidade a partir da criação artística

Orientador: Joel Birman

Data de defesa: julho

Esta dissertação tem por objetivo pensar, tendo como referência a metapsicologia freudiana, a questão da singularidade a partir do modelo da criação artística. Neste contexto, entendemos o conceito de sublimação, apresentado nas formulações freudianas a partir do conceito de pulsão de morte, como uma possível saída para o mal-estar. 0 que se coloca como específico aqui é uma consideração das relações entre psicanálise e música, da criação artística musical e das questões que o pensamento musical e a estética musical moderna podem nos colocar, quando tomamos o artista como intérprete do seu tempo e a singularidade como forma de o sujeito se inscrever na cultura.

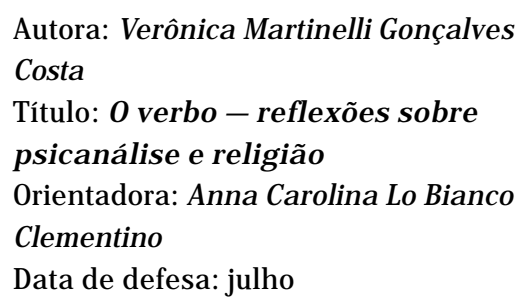

A dissertação em questão visa apresentar um quadro geral da problemática da religião como apresentada por Freud - mais especificamente daquela que pode ser apreendida no âmbito de uma tradição judaico-cristã. Para tanto utiliza as noções de sublimação, ilusão eW eltanschauung (visão do mundo). Além disso, proponho uma reflexão sobre as funções que Freud atribui à religião e, também, sobre a articulação dos símbolos e rituais sagrados com a patologia - nomeadamente a neurose obsessiva e a paranóia. Todo esse quadro pretende ser uma forma de abordagem de um tema mais geral: o discurso que, no cerne da metapsicologia freudiana, se produz sobre a cultura. Tema este que se torna relevante quanto percebemos que a psicanálise se constrói para dar conta das queixas de um sujeito que é, para ela, desde sempre, marcado pela linguagem e pelas desventuras da cultura. Assim, meu objetivo não recai sobre a tentativa de construir uma psicanálise aplicada aos problemas religiosos, mas sim sobre a necessidade de pensarmos, constantemente, a respeito dos conceitos que alicerçam o nosso saber. 
Autor: Daniel Menezes Coelho

Título: Psicanálise e modernidade: mais um esforço

Orientador: Waldir Beividas

Data de defesa: julho

Esta dissertação tem como principal objetivo a investigação das relações que a psicanálise guarda com a modernidade, e que encaminhamentos podem ser dados a estas relações. Se a psicanálise é intrinsecamente moderna, como se afirma, é necessário a definição do que esse termo significa e onde podemos encontrar 0 corte, mesmo que lógico, entre modernidade e antiguidade. Desse modo, entra em nossa consideração a ci ência, que tem sido apontada freqüentemente como 0 pensamento que opera esse corte entre 0 antigo e o novo, e a filosofia, que da apropriação dessa ciência faz o seu assunto todo o período desde o surgimento da ciência até hoje, na tentativa de formalizar o que a ciência requer do pensamento. Da psicanálise, diremos que ela é, por um lado, auge desse movimento filosófico, na medida em que o significante disjunto da significação proposto por Lacan é certeiro na formalização do pensamento sem qualidades apontado pela filosofia como o pensamento exigido pela ciência, e por outro, promove seu desmantelamento, na medida em que é levada a reconhecer que o significante não se dá sem efeitos de significação. Daí seremos levados a situar a psicanálise a partir de uma outra epistemologia, na qual a ciência não requer o pensamento sem qualidades, mas justamente reconhece a impossibilidade de tal projeto. Não se tratará, então, de esvaziamentos das qualidades, mas de um vetor de abstração que, por ser impossível enquanto duração, deve ser requisitado a todo momento.
Autor: Maurílio Rossi

Título: Implicações da ética na clínica psicanalítica das psicoses

Orientadora: Anna Carolina Lo Bianco

Data de defesa: dezembro

Esta dissertação tem como objetivo realizar um recenseamento do desenvolvimento de Freud e de Lacan a respeito dos conceitos de transferência, das psicoses e da ética da psicanálise. Para tanto, procuramos apontar na obra de ambos os momentos de impasses nas construções destes conceitos, bem como as respostas dadas por cada um deles para superação destes impasses. 0 ponto de fechamento desta dissertação procura relacionar as incidências da ética da psicanálise no manejo transferencial feito pelo analista na clínica das psicoses.

\section{DOUTORADO}

\section{Autora: Angela Cavalcanti Bernardes \\ Título: Elaboração de saber na análise: um tratamento do impossível \\ Orientadora: Ana Beatriz Freire \\ Data de defesa: abril}

A construção do saber inconsciente na experiência de uma psicanálise tem efeitos sobre a relação do sujeito com seu gozo. A questão que se coloca aqui é a de saber como a palavra, o significante, opera sobre o real que nos termos de Freud se encontra na satisfação pulsional. Percorrendo as obras de Freud e Lacan verificamos o percurso que os levaram, cada um a seu modo, a acentuar cada vez mais o fator pulsional no trabalho de transfe- 
rência. A noção freudiana de trabalho analítico, Durcharbeitung, assim como a elaboração lacaniana sobre a estrutura discursiva na tran sferência são estudadas aqui para conceituar a psicanálise enquanto práxis no sentido lacaniano, a saber: um tratamento do real pelo simbólico.

Autor: Francisco Leonel de Figueiredo Fernandes

Título: Psicanálise e formalismo

Orientadora: Ana Beatriz Freire

Data de defesa: agosto

Nosso propósito foi o de examinar a presença de formal ismos matemáticos na psicanálise. Em primeiro lugar, estabelecemos a noção do que seja formalismo. Para isso investigamos a história da matemática no sentido de observar o percurso conceitual que desembocou na idéia de formalismo. Examinamos a seguir como a ciência moderna (Descartes, Galileu e Newton) foi determinada, do ponto de vista das idéias, pelo avanço de uma concepção mais formalizada de seus conceitos maiores (número, ordem, contínuo, etc.) . A ciência só foi possível, através do passo de Descartes e Fermat, com a "invenção" da álgebra propriamente dita. Finalmente, abordamos como 0 "formal" teve lugar na teorização de Freud e, posteriormente, de Lacan. Quanto a Freud, demonstramos que certos aspectos do conceito de real - o número real como escrita do impossível - sustentam alguns conceitos maiores da psicanálise, tais como o de recalque primário e 0 de pulsão. Em Lacan, o "formal" é muito mais evidente. Lacan é um autor que acompanhou todo debate em torno da questão dos fundamentos da matemática no início do século XX. Para ele é bastante claro que a ciência é "matematização" do real. Nosso trabalho deteve-se em particular na sua utilização de conceitos da topologia algébrica (as superfícies) e geral (noção de vizinhança) para estabelecer os conceitos psicanalíticos.

Autora: Maria Isabel de Andrade Fortes

Título: 0 sentido do sofrimento: a positividade da dor em Freud

Orientadora: Anna Carolina Lo Bianco

Data de defesa: agosto

Este trabalho tem por objetivo examinar o sofrimento a partir de duas dimensões, sendo uma positiva e a outra negativa. A positividade da dor aponta para um caminho no qual o sofrimento é também vitalidade. Por outro lado, o sofrimento visto como uma coisa negativa conduz a uma via de paralisação e mortificação do sujeito. Buscamos apresentar um paradigma da dor a partir da discussão de alguns conceitos da metapsicologia freudiana. Trabal hamos também os sentidos do sofrimento em Nietzsche, a partir da concepção das forças ativas e reativas. Dividimos a tese em quatro capítulos. No primeiro capítulo, fazemos um estudo da relação do sujeito da atualidade com a dor, demonstrando a presença do hedonismo na cultura atual. Contrapomos o hedonismo ao erotismo, na medida em que $o$ primeiro rechaça o sofrimento e 0 segundo implica necessariamente a passagem pela dor. No capítulo seguinte, discutimos a dor e o prazer. Apontamos uma positividade da pulsão de morte em Freud, a partir da idéia de que a força disruptiva desta última é 0 que possibilita a chegada do novo. No terceiro capítulo, desenvolvemos a noção de masoquismo, buscando discriminar diferen- 
tes níveis desta experiência e valorizando a figura do masoquismo erógeno nas teorizações freudianas. No último capítulo, desenvolvemos a transi ção do sofrimento como mal para o sofrimento como força, sendo este o próprio processo de encontrar na dor a sua positividade.

Autora: Adelina Helena Fonseca L.

Pinheiro de Freitas

Título: $\mathbf{0}$ pai real e o término da

análise

Orientadora: Anna Carolina Lo Bianco

Data de defesa: dezembro

Este trabalho desenvolve 0 tema do destino do pai no processo analítico e as implicações para seu término. Podemos afirmar que uma análise questiona a posição paterna. Entretanto, sustentamos que existem nuances importantes nesta consideração, que procuramos desenvolver ao longo do texto. Se como afirma Lacan é possível prescindir do pai na condição de servir-se dele, nosso intuito foi verificar os aspectos a que esta proposta poderia remeter. Outro ponto importante em nosso percurso é a articulação desta função com a posição do analista. É desde o desejo do analista que este opera, e sua resposta na transferência está necessariamente ligada a isto.
Autora: Maria Silvia Garcia Fernandez

Hanna

Título: A transferência na psicose: uma questão

Orientadora: Ana Beatriz Freire

Data de defesa: dezembro

A presente tese visa discutir o estatuto do laço que os sujeitos inseridos numa estrutura psicótica estabelecem com 0 analista. 0 trabalho de pesquisa realiza um recorte dentro do vasto campo da psicose, delimitando como objeto de trabaIho as psicoses que se caracterizam por constituir sistemas delirantes. Servindose das balizas propostas por $\mathrm{S}$. Freud e J. Lacan, a tese estabelece uma íntima relação entre a estrutura da psicose e o conceito de transferência. Delimitando o lugar do objeto e do sujeito, tece uma série de considerações em torno da transferência delirante (expressão proposta para designar o laço na psicose), indicando os possíveis lugares para a condução do tratamento e propondo uma manobra que permita abrir passo para a construção de um recurso que possibilite ao psicótico encontrar uma estabilização na sua estrutura. 